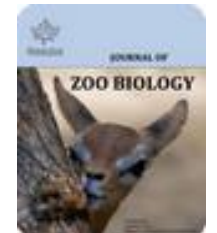

\title{
The Stomach Morphology and Contents of the Chinese Pangolin (Manis pentadactyla)
}

Na Xu', Yue Min', Shibao Wu, Fuhua Zhang School of Life Sciences, South China Normal University, Guangzhou, 510631, China.

\section{A R T I C L E I N F O}

\section{Article History}

Received: April 08, 2020

Revised: August 17, 2020

Accepted: September 11, 2020

\section{Keywords}

Chinese Pangolin

Stomach

Morphology

Contents

Adaptation

\section{A B S T R A C T}

To better understand the critically endangered Chinese pangolin (Manis pentadactyla)'s adaptation to highly specialized prey and to enrich the acknowledge of this species' natural diet, we performed anatomic observation and contents analysis on the stomach of accidental death of Chinese pangolin. The stomach is C-shaped and consists of the cardia, fundus, body, and pylorus, weight $136.5 \mathrm{~g}$, volume $120 \mathrm{ml}$, and the curve length of lesser and greater curvatures is $9.1 \mathrm{~cm}$ and $25.1 \mathrm{~cm}$, respectively. The inner wall of the stomach is covered with the milky layer of mucosa which forms 9-10 spiral folds lapping the cardia and fundus, arranged alternately with ditches and ridges, accounting for approximately $30 \%$ of the inner surface of the stomach. These folds are soft to touch and reddish. The inner surface of the greater curvature has a pie-shaped appendix that protrudes and opens into the stomach cavity; it looks like fat tissue and is kermesinus. The pyloric tunica muscularis is thick, and the pyloric sphincter is developed. There is a mulberry-like bulge at the pylorus, named the pyloric pillow, and the pyloric gland lies below it; the pyloric pits are the size of a pen tip. The surface of pyloric pillow and nearby it is covered with yellowish spinous processes and pyloric teeth. The main component of the stomach contents was found to be the diced chitin exoskeletons of Carebara sp. with small amounts of straw, roots, and small stones, which were evenly mixed with stomach juices $(\mathrm{pH} 3)$. The fresh weight of the contents was $29.03 \mathrm{~g}$, which accounted for approximately one-quarter of the stomach cavity volume. This study has shown that there was an adaptation of the stomach of Chinese pangolin to its diet.

\footnotetext{
*Corresponding Author: Shibao Wu

tThese two authors contributed equally to this work and should be considered co-first authors.

Email: wushibao@163.com Tel: 0086-20-85211372; Fax: 0086-20-85211372.

(C) The Author(s) 2020.
}

\section{INTRODUCTION}

Chinese pangolins belong to the order Pholidota, the family Manidae under Mammalia (Corbet and Hill, 1992; Gaubert and Antunnes, 2005), are very specialized and unique mammal covered with scales with low body temperature, no teeth, feed only on ants and termites $(\mathrm{Wu}$ et al., 2005a,b), distribute mainly south of the Yangtze River in China, including Hainan and Taiwan, and a few are found in Thailand, Laos, Vietnam, Myanmar, Nepal, and other countries bordering China (Wu et al., 2002). Due to overhunting and habitat destruction, they are on the verge of extinction (Wu et al., 2005b). This species has been listed as Critically Endangered on the IUCN Red List of Threatened Species (Challender et al., 2019).

The stomach is an important digestive organ. It temporarily holds food, secretes stomach juices, and initially digests food and pushes it into the duodenum. Understanding the morphological and structural characteristics of the animal's stomach helps us to understand the food differentiation, specialization, and adaptability of animals. Simultaneously, it can help with the prevention, treatment, and diagnosis of stomach 
diseases. However, knowledge of the Chinese pangolin stomach is very little, because Chinese pangolins that are extremely endangered animals strictly ban to capture for research. Making research samples are very difficult to obtain. In this paper, we grossly dissected a stomach of a healthy Chinese pangolin, and its morphological and structural characteristics were observed and measured, and its contents were analyzed to understand the feeding characteristics of Chinese pangolins. The purpose of this study was to understand the structural characteristics of the Chinese pangolin stomach and its adaptability to food specialization. The findings would provide the necessary knowledge for preventing disease and diagnosing and treating captive Chinese pangolins, designing artificial feed, and evaluating their daily feed intake.

\section{MATERIALS AND METHODS}

The stomach was obtained from a healthy Chinese pangolin (male, $6.5 \mathrm{~kg}$ ) that died unexpectedly. After washing the blood and impurities from the stomach surface, the external morphology was observed, and the related indexes were measured. With the cardia as the starting point, the stomach was cut along the lesser curvature to the pylorus, and the contents were removed, weighed, and measured for $\mathrm{pH}$. The stomach wall was cleaned to observe and evaluate the internal morphology. The stomach contents were placed in a Petri dish containing distilled water and were analyzed after being sufficiently hydrated and dispersed.

\section{RESULTS}

\section{External Morphological Observations}

The stomach was C-shaped and weighed $136.5 \mathrm{~g}$ empty. It had a volume of $120 \mathrm{~mL}$ and a stomach axis diameter of $11.8 \mathrm{~cm}$. It was flesh-colored, fresh, shiny, and soft to touch. It consisted of the cardia, pylorus, fundus, and body (Figure 1). There were two openings: one in the cardia (Figure 1, Eso) where the oesophagus enters the stomach and an outlet called the pylorus (Figure 1, Duo) connected to the duodenum, where the chyme passes into the small intestine. The outwardly convex arcuate edge, called the greater curvature (Figure 1, Mg-G) of the stomach, was $25.1 \mathrm{~cm}$ in length. The inwardly concave arcuate edge, called the lesser curvature of the stomach, was $9.1 \mathrm{~cm}$ in length. Near the pylorus, the curvature folds inwardly into an angular incisure (Figure 1, Ga). Near the cardia, the bulgy part is called the fundus (Figure 1, b), and the middle part of the stomach is called the body (Figure 1, c). The fundus, body, and pylorus account for approximately one-third of the stomach volume each. The walls of the fundus and body are thin, elastic, and pink due to abundant capillaries (Figure 1). The middle part of the greater curvature is slightly darker and bulges outward slightly. It has a pie-like structure resembling fat tissue called the fundus gland (Figure 1, OG). The pyloric muscles are weak in elasticity and pink (Figure 1, d). The measurements of the stomach are shown in Table 1.

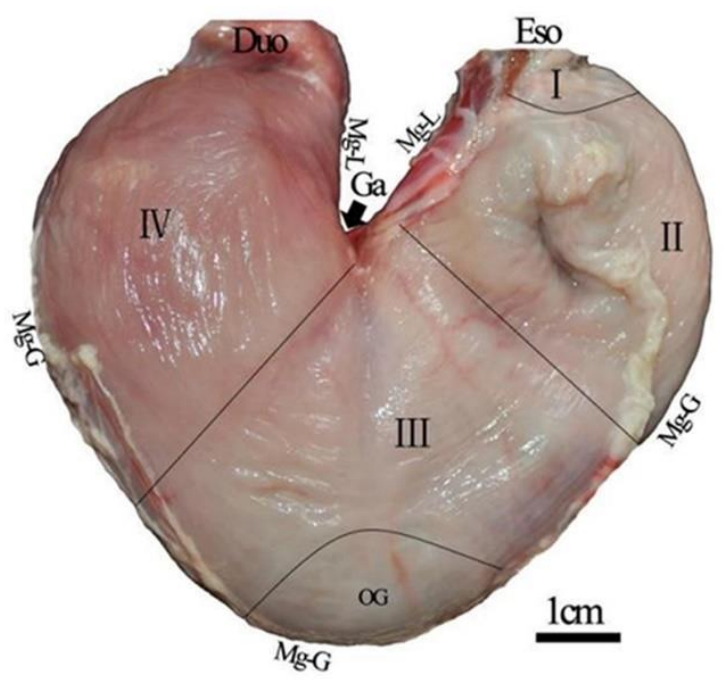

Figure 1. External view of the Chinese pangolin stomach. Eso, cardia; Duo, pylorus; I, caecus minor ventricular; II, fundus; III, the body; IV, pylorus; OG, acid-secreting gland; Mg-L, lesser curvature; Mg-G, greater curvature; Ga, angular notch. 
Table 1. The measurement of the stomach of Chinese pangolin

\begin{tabular}{|c|c|c|c|c|c|c|c|c|}
\hline \multirow{2}{*}{$\begin{array}{l}\text { Weight } \\
\text { (g) }\end{array}$} & \multirow{2}{*}{$\begin{array}{l}\text { Volume } \\
(\mathrm{mL})^{*}\end{array}$} & \multirow{2}{*}{$\begin{array}{l}\text { Diameter of the } \\
\text { stomach axis } \\
(\mathrm{cm})^{* *}\end{array}$} & \multirow{2}{*}{$\begin{array}{c}\text { Greater } \\
\text { curvature } \\
(\mathrm{cm})\end{array}$} & \multirow{2}{*}{$\begin{array}{c}\text { Lesser } \\
\text { curvature } \\
(\mathrm{cm})\end{array}$} & \multicolumn{4}{|c|}{ Parietal thickness (mm) } \\
\hline & & & & & $\begin{array}{c}\text { Cardia } \\
\text { part }\end{array}$ & Cardia & $\begin{array}{c}\text { Corpora } \\
\text { ventricle }\end{array}$ & $\begin{array}{c}\text { Pylorus } \\
\text { part }\end{array}$ \\
\hline 136.53 & 120 & 11.80 & 25.1 & 9.1 & 3.0 & 3.0 & 1.5 & 11.4 \\
\hline
\end{tabular}

*Water injection method. ${ }^{* *}$ The diameter of the stomach axis refers to the length of the leftmost end of the stomach fundus to the right end of the stomach body.

\section{Internal morphology}

The inner wall is covered with a milky layer. In the relaxed state, the stomach mucosa forms 9-10 spiral folds lapping the cardia and fundus that form alternate ditches (width $3.1 \mathrm{~mm}$ ) and ridges (height $2.3 \mathrm{~mm}$ ) (Figure 2;
Figure 3). There are 20-24 rows of folds arranged longitudinally on both sides of the fundic glands (Figure 2). The plica feels soft and is reddish, accounting for approximately $30 \%$ of the inner wall of the stomach. The ditches of the plica are filled with chyme (Figure 3, b).

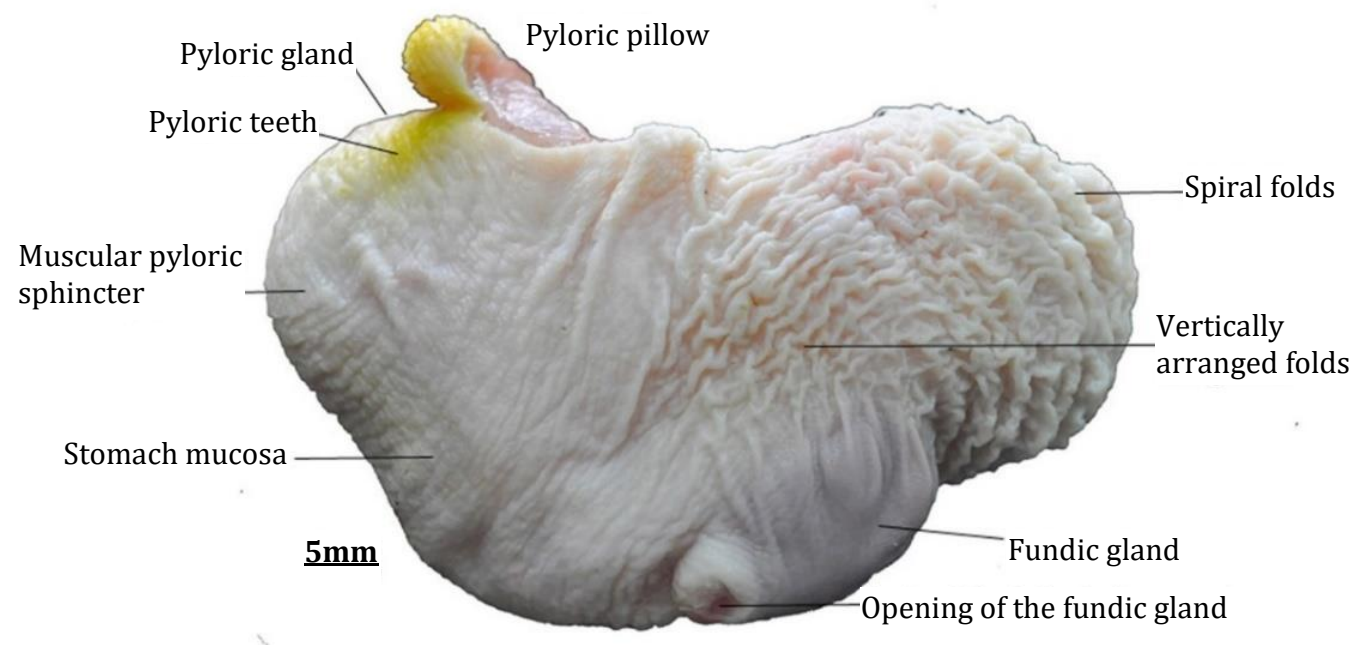

Figure 2. Internal morphology of the Chinese pangolin stomach.

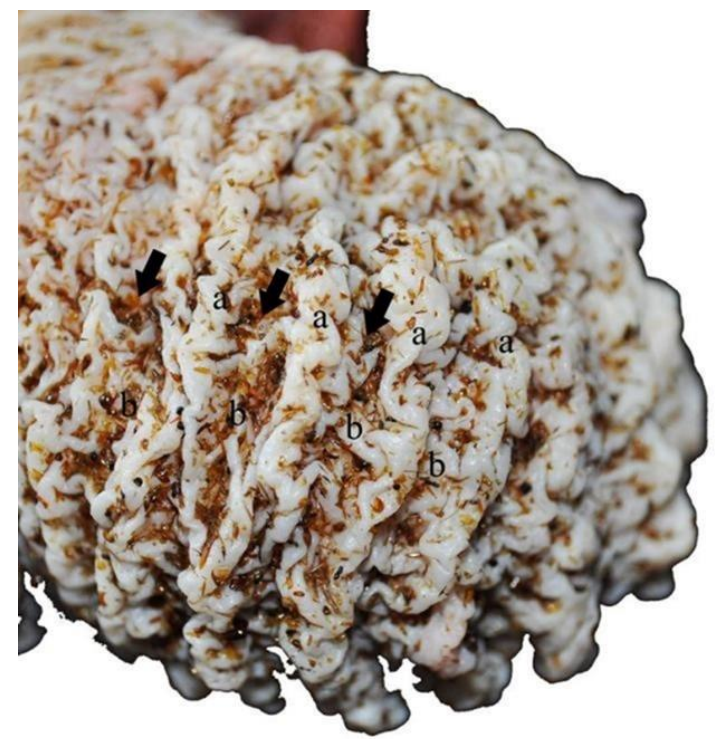

Figure 3. Spiral folds of the Chinese pangolin stomach. Chyme is full of ridges (a) and ditches (b) (arrow). 
The fundic gland is embedded in the middle of the greater curve of the stomach and protrudes into the stomach cavity. It looks like fat tissue, kermesinus, with a smooth appearance, and there are 7 depressions on the edge of this gland. It measures $4.4 \mathrm{~mm}$ thick, $3.6 \mathrm{~cm}$ long, and 3.6 $\mathrm{cm}$ wide and has an opening into the stomach cavity through which the secreted stomach juice is injected (Figure 4).

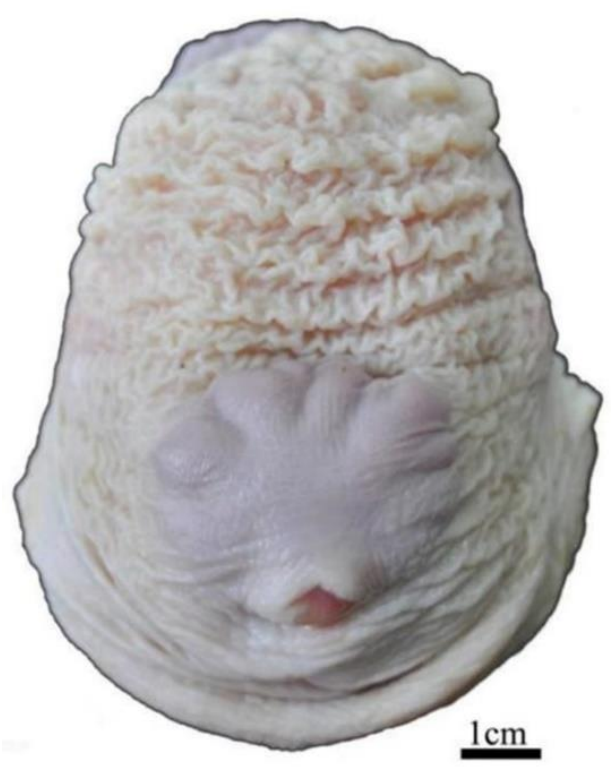

Figure 4. Fundic gland of the Chinese pangolin stomach.

The pyloric sphincter is well developed (Figure 5E). There is a mulberry-like bulge on the inner side of the pylorus, whose base is attached to the muscle of the lesser curvature of the stomach, and the free end is convex toward the pyloric cavity (Figure 5B). It is $21.0 \mathrm{~mm}$ long, $11.3 \mathrm{~mm}$ wide, and $10.8 \mathrm{~mm}$ thick, yellowish, with a high degree of keratinization. There are pyloric teeth on and near the surface of the pylorus, tufted with yellowish tapered spinous protrusions (Figure 5C), and a number of scattered nib-sized pits below it, which are the openings of the pyloric glands (Figure 5D).
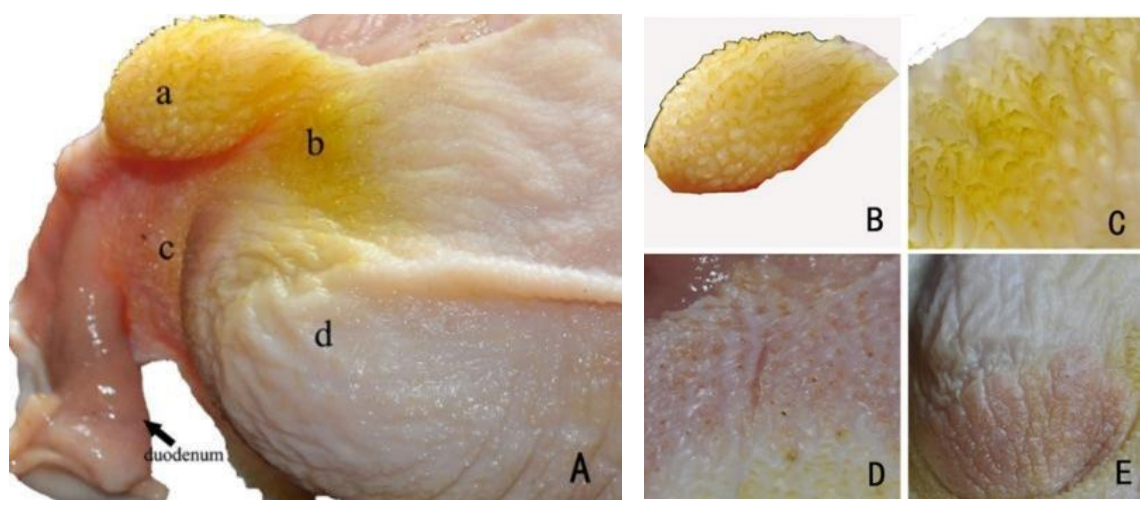

Figure 5. The pylorus of the Chinese pangolin stomach. A, a) pyloric pillow; b) pyloric tooth; c) pyloric gland; d) muscular pyloric sphincter; B-E show the details of a-d, respectively, in A.

\section{Stomach Contents}

The stomach contents consisted of brown-black debris (a, b), most of which was the remains of ant chitin exoskeletons, with small amounts of straw, roots, and small stones (Figure 6g, h; Table 2; Figure 7). No termites or remains of other insects were found in the stomach. The heads of worker ants (Figure 6d) and soldier ants (Figure 6e), thoraces of adult ants (Figure 6f), and pupae 
(Figure 6c; Table 2) were identified, whereas no larvae, eggs, or whole ants were seen. The ants, belonging to the genus Carebara, exhibited nine segments in the antennae, a single body, no compound eyes, and a lack of double longitudinal ridges in the middle of the lip base (Wu and
Wang, 1995). The stomach contents were mixed with stomach juice to form chyme, which accounted for approximately one-quarter of the stomach volume and had a $\mathrm{pH}$ of 3.0 and fresh weight of $29.3 \mathrm{~g}$ (Table 2).

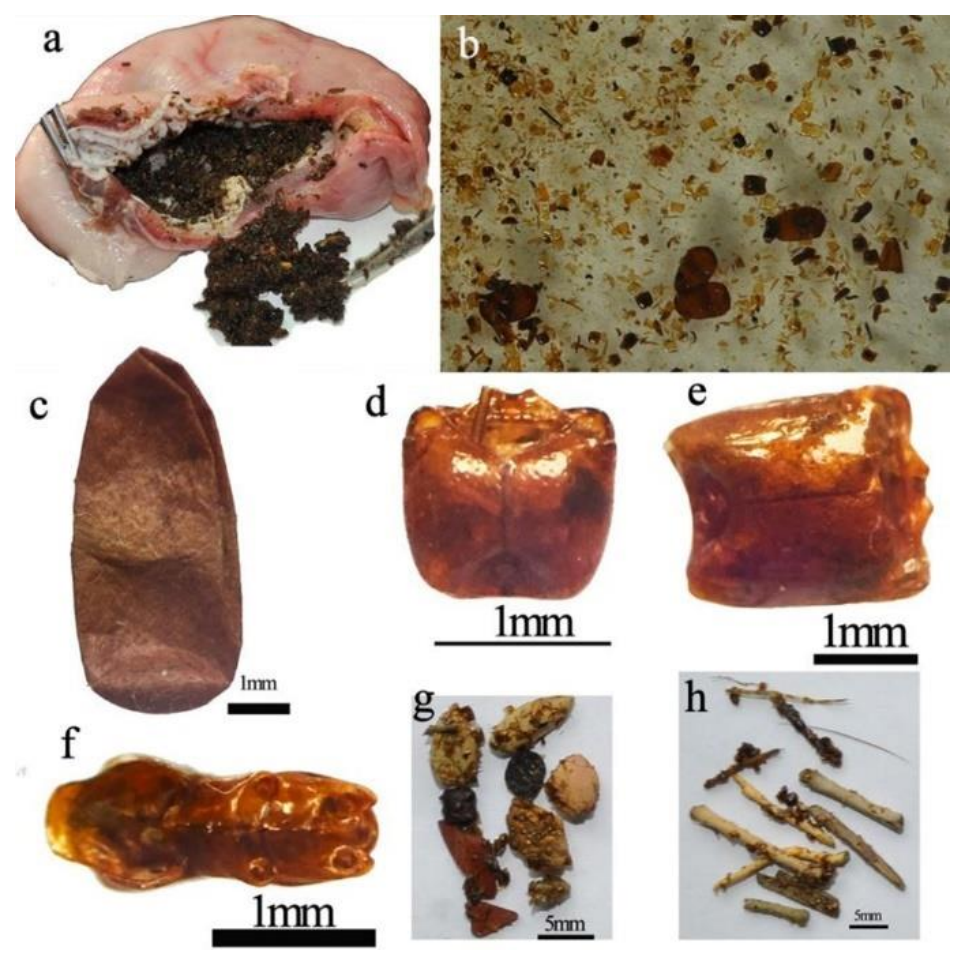

Figure 6. The stomach contents of a Chinese pangolin. a) The stomach contents of a Chinese pangolin; b) the stomach contents suspended on the water surface in a culture dish; c) pupae; d) worker's head; e) soldier's head; f) worker's thoraces; g) soldier's thoraces; h) small stones.

Table 2. The stomach contents of a Chinese pangolin.

\begin{tabular}{cccccc}
\hline \multirow{2}{*}{$\begin{array}{c}\text { Fresh weight } \\
(\mathrm{g})\end{array}$} & $\mathrm{pH}$ & \multicolumn{3}{c}{ Ants } & Pupae length $\times$ width \\
\cline { 3 - 5 }$(\mathrm{cm})$ & $\begin{array}{c}\text { Number of } \\
\text { pupae }\end{array}$ & $\begin{array}{c}\text { Number of ant } \\
\text { thoraces }\end{array}$ & $\begin{array}{c}\text { Piamer of small stones } \\
(\mathrm{mm})\end{array}$ \\
\hline 29.3 & 3 & $0.4 \times 0.2$ & 338 & 1446 & $1-6$ \\
\hline
\end{tabular}

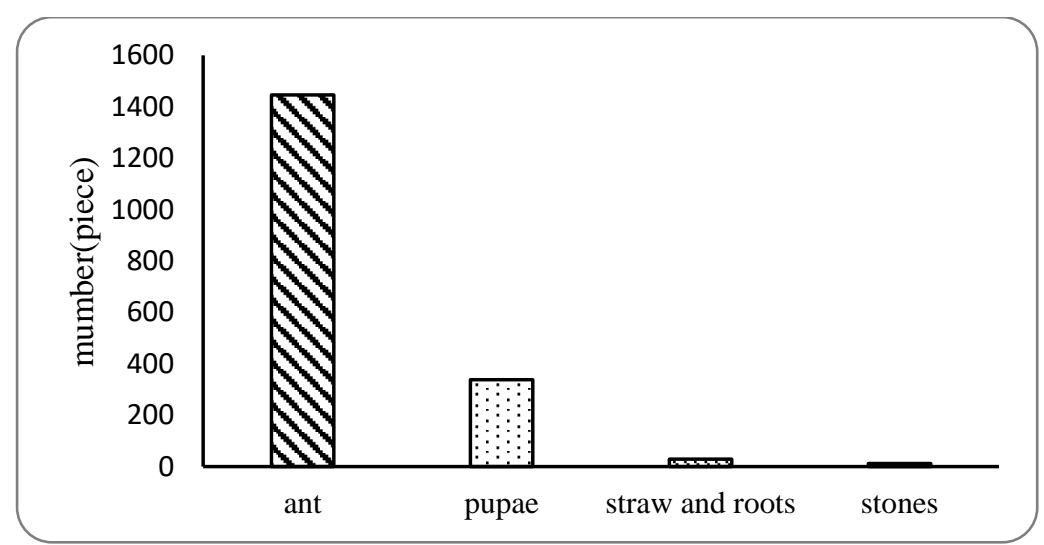

Figure 7. Quantity of the stomach contents of a pangolin. 


\section{DISCUSSION}

\section{Stomach Structure and Function}

Pangolins have no teeth and feed mainly on chitin-rich ants and termites, which contain formic acid. The chitin exoskeleton envelops nutrient-rich fats and proteins. Chitin is a very tough organic substance made from highmolecular-weight polysaccharides which are hard to break. We found that the structure of the Chinese pangolin stomach was adapted to the pangolin's lack of teeth and a specialized diet.

The folds of the Chinese pangolin stomach were well developed, tough, and elastic, with a keratinized surface. The ditches were wide and deep, and the ridges bulged outward. There were both spiral and longitudinal folds (Figure 2; Figure 3), which increase the surface area and volume, enabling storage of more food in winter when food is scarce. When the stomach is filled, these folds help mix and grind the food and perform mechanical digestion, making up for the pangolin's lack of teeth. Others have also reported on the keratinization of the surface of the Chinese pangolin's stomach wrinkles (Lin et al., 1996; Krause and Leeson, 1974).

The pyloric muscles are very well developed (Figure 5); the stomach wall is significantly thickened with a high degree of keratinization. It resembles the muscular stomach of birds (Sun, 2014) and can exert a powerful grinding effect on the chitin of its prey. It also protects the tunica muscular is from damage. Squamous keratinization of epithelial cells in the corpus and pylorus of the Chinese pangolin and tree pangolin (Manis tricuspis) has also been reported (Krause and Lesson, 1974; Ofusori et al., 2008) speculated that it is related to grinding and protecting the stomach.

The pylorus pillow (Figure 5) delays emptying of the stomach contents and prevents the intestinal contents from refluxing into the stomach. Some people have mistakenly identified the pyloric pillow as a stomach tumour (Chen et al., 1984; Chen et al., 1986). The teeth on the surface of the pylorus can be interlaced to cut food (Figure 5). The stomach of the Malayan pangolin (Manis javanica) has the same structure (Evgenyeva and Can, 2013).

Stomach fundus glands have been reported in Chinese, Malayan, and tree pangolins (Lin et al., 2015; Imai et al., 1973; Krause and Lesson, 1974; Ofusori et al., 2008) and are very similar morphologically among all three species. The developed fundic glands may be associated with the
Chinese pangolin's diet of chitin-rich ants and termites. Chitin is digested by endogenous enzymes present in the typical mammalian gastrointestinal tract, especially acidic mammalian chitinase (AMCase) (Boot et al., 2001). Ma et al. (2018) found that Malayan pangolin AMCase mRNA and protein are expressed mainly in the fundic gland, suggesting that it is the main site of AMCase synthesis. The fundic gland cells include the mucous neck, chief, parietal, and endocrine cells (Nisa et al., 2010), which secrete hydrochloric acid, pepsin, and mucus. We speculate that the stomach fundic glands of Chinese pangolins also have this function.

Malayan pangolins also have a pyloric gland that is similar to the Chinese pangolin pyloric gland, and this gland secretes strong alkaline mucus into the duodenum and neutralizes stomach acids to protect the duodenal mucosa (Imai et al., 1973; Telford and Bridgman, 1995; Nisa et al., 2010). Accordingly, we speculate that the Chinese pyloric gland also neutralizes stomach acids, which may also include formic acid from its food, to prevent duodenal self-digestion. The pyloric gland of the Malayan pangolin is composed of mucous cells (Nisa et al., 2010), which secrete acidic glycoproteins that cover the surface of the pylorus and can be used for lubrication and facilitating the entry of chyme into the duodenum; this, in turn, can reduce the mechanical damage to the pyloric wall caused by the rough ant debris. The pyloric gland of the Chinese pangolin likely also possesses this function.

\section{Comparison of Normal and Abnormal Stomach Morphology}

This stomach mucosa was thick and elastic, with developed plica and no lesions. It was a normal stomach. We have observed that in abnormal Chinese pangolin stomachs, muscle layer disappears, the gastric mucosa sheds (Figure 8b), the stomach wall is as thin as paper (Figure 8a, b) with no elasticity, the gastric wall is transparent, the folds disappear (Figure 8b, c), and with ulceration and bleeding points(Figure 8c, d). Most of the pangolins that died during rescue or conservation at South China Normal University had abnormal stomach conditions. We postulate that stomach disease is one of the main causes of death of Chinese pangolins in captivity. According to reports, $67.7 \%$ of Chinese pangolins at Taipei Zoo died of gastrointestinal diseases (Chin et al., 2012). Our morphological findings in the normal Chinese pangolin stomach can be used as a reference for the diagnosis of pangolin gastropathy. 


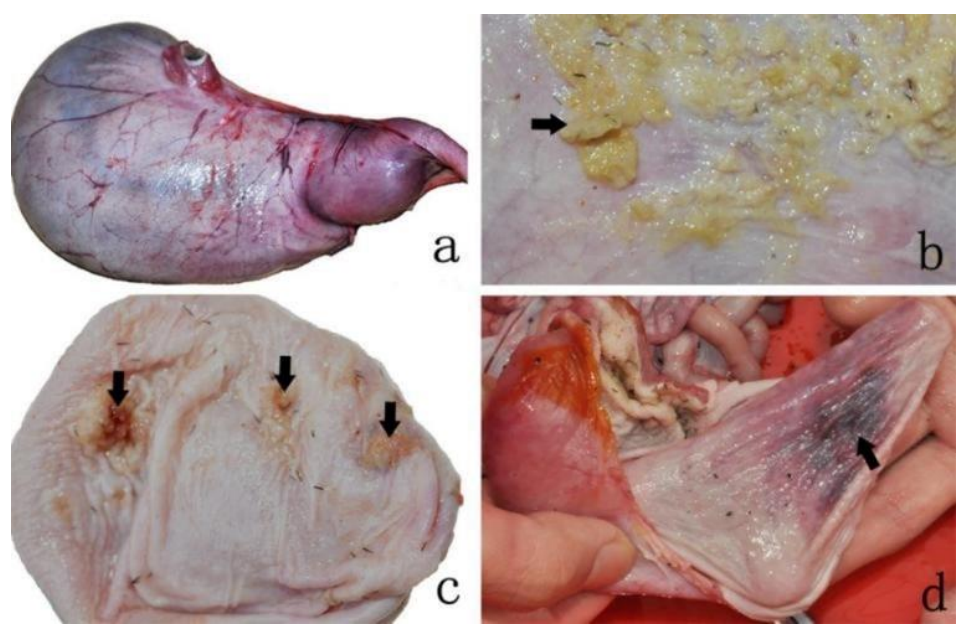

Figure 8. Abnormal stomachs photographed by Shibao Wu at South China Normal University Pangolin Artificial Rescue and Conservation Research Base, 2016. a) Externally, a diseased stomach is characterized by a thin transparent wall, no muscle, and a bright surface and is filled with gas and chyme; b) mucosal abscission of the stomach wall (the arrow indicates unshed stomach mucosa); c) a stomach ulcer (arrow); d) stomach bleeding, the disappearance of the tunica muscularis, complete loss of the stomach mucosa.

\section{Stomach Contents}

The ants found in the stomach (a nine-segment genus) in the present study have not been recorded previously in the pangolin diet (Wu et al., 2005a; Zhang, 2004), which enriched the recipe of the Chinese pangolin. There were no complete ants in the stomach contents, and the tough chitin exoskeletons had been completely ground into debris, indicating the power of the stomach. In addition to ant debris, the stomach contents contained incompletely digested pupae (Figure 6c; Table 2), indicating that pangolins are not selective and feed on adult ants and pupae. The pupa is rich in protein and makes a relatively large contribution to the pangolin diet. When in captivity, pangolins should also be fed pupae to ensure balanced nutrition. There were also some small stones (Figure 6g; Figure 7; Table 2) in the stomach. Previous studies reported that small stones help grind the chitin exoskeleton (Wu et al., 2005a; Kingdon, 1971). The stomach contents weighed $29.3 \mathrm{~g}$ and accounted for approximately one-quarter of the stomach volume. It is estimated that the stomach can accommodate up to 117.2 $\mathrm{g}$ of food, accounting for $1.8 \%$ (117.2/6500) of the total body weight, and this can be used as a reference for feeding captive pangolins.

\section{CONCLUSION}

Chinese pangolin is a critically endangered species. The stomach is an important digestive organ. This study has shown that there was an adaptation of the stomach of
Chinese pangolin to its diet. Moreover, it might be unsuitable to feed Chinese pangolin with only adult ants. So, pangolins in captivity should be fed pupae and adult ants to ensure balanced nutrition. Understanding the morphological and structural characteristics of the animal's stomach helps us to understand the food differentiation, specialization, and adaptability of animals. Simultaneously, it can help with the prevention, treatment, and diagnosis of stomach diseases.

\section{ACKNOWLEDGEMENTS}

We are grateful to Professor Houfeng Li of Pingtung University in Taiwan for his identification of ants. This project was supported by the National Natural Science Foundation of China (No. 31572286, 31702029), the Guangzhou Science and Technology Innovation Program (No. 201804010475), and the Guangdong Provincial Natural Science Foundation (S2013010013356) for funding this research.

\section{CONFLICT OF INTEREST}

All authors declare that there is no conflict of interest.

\section{AUTHOR'S CONTRIBUTION}

Methodology: Shibao Wu, Yue Min, Fuhua Zhang

Resources: Shibao Wu, Fuhua Zhang

Data analysis and writing the article: $\mathrm{Na} \mathrm{Xu}$, Yue Min Supervision: Shibao Wu 


\section{REFERENCES}

Boot, R.G., E.F.C. Blommaart, E. Swart, K. Ghauharali-van der Vlugt, N. Bijl, C. Moe, A. Place and J.M.F.G. Aerts. 2001. Identification of a novel acidic mammalian chitinase distinct from chitotriosidase. Journal of biological chemistry, 276: 6770-6778.

Challender, D., S. Wu, P. Kaspal, A. Khatiwada, A. Ghose, N. Ching-Min Sun, R.K. Mohapatra and T. Laxmi Suwal. 2019. Manis pentadactyla (errata version published in 2020). The IUCN Red List of Threatened Species 2019: e.T12764A168392151. https://dx.doi.org/10.2305/IUCN.UK.20193.RLTS.T12764A168392151.en.

Chen, Y.H., J.Q. Xu, Z.H. Chen and Z.D. Xiao. 1986. Study on gastric carcinoma and its etiology in Chinese pangolin. Acta zoological sinica, 32(1): 96-97.

Chen, Y.H., J.Q. Xu, Z.H. Chen, Z.D. Xiao and L.H. Xu. 1984. On the gastric tumors of Chinese pangolin. Acta zoological sinica, 30(2): 105-108.

Chin, S.C. P.H. Yu, Y.T. Chan, C.Y. Chen, J.C. Guo and L.S. Yeh. 2012. Retrospective Investigation of The Death of Rescued Formosan Pangolin (Manis pentadactyla pentadactyla) during 1995 and 2004. Taiwan Veterinary Journal, 38(4): 243-250.

Corbet, G.B. and J.E. Hill. 1992. The mammals of the Indomalayan region: A systematic review. Oxford University Press, London, UK.

Evgenyeva, T.P. and D.N. Can. 2013. Morphofunctional alterations in the stomach of the Sunda pangolin (Manis javanica Desmarest, 1822, Pholidota, Mammalia) associated with specific nutrition features. Doklady Biological Sciences, 451(1): 241243.

Gaubert, P. and A. Antunes. 2005. Assessing the taxonomic status of the Palawan pangolin Manis culionensis (Pholidota) using discrete morphological characters. Journal of Mammalogy, 86: 1068-1074.

Imai, M., T. Shibata, T. Mineda, Y. Suga and T. Onouchi. 1973. Histological and histochemical investigations on the stomach of man, Japanese monkey (Macaca fuscata yakui) and other animals. $\mathrm{V}$. On the stomach of the pangolin (Manis pentadactyla Linne). Okajimas folia anatomica Japonica, 49(6): 433-453.

Kingdon, J. 1971. East African Mammals. An Atlas of Evolution in Africa, Vol.1. Academic Press, London, UK.
Krause, W.J. and C.R. Leeson. 1974. The stomach of the pangolin (Manis pentadactyla) with emphasis on the pyloric teeth. Cells Tissues Organs, 88(1): 1-10.

Lin, H.L., R. Huang, J.C. Yang and X.M. Liu. 1996. Study on the microstructure of pangolin's digestive organs. Chinese wildlife, 93(5): 33-36.

Lin, M.F., C.Y. Chang, C.W. Yang and E.S. Dierenfeld. 2015. Aspects of digestive anatomy, feed intake and digestion in the Chinese pangolin (Manis pentadactyla) at Taipei zoo. Zoo Biology, 34(3): 262-270.

Ma, J.E., L.M. Li, H.Y. Jiang, X.J. Zhang, J. Li, G.Y. Li and J.P. Chen. 2018. Acidic mammalian chitinase gene is highly expressed in the special oxyntic glands of Manis javanica. FEBS Open Bio, 8(8): 1247-1255.

Nisa, C., S. Agungpriyono, N. Kitamura, M. Sasaki, J. Yamada and K. Sigit. 2010. Morphological Features of the Stomach of Malayan Pangolin, Manis javanica. Anatomia Histologia Embryologia, 39(5): 432-439.

Ofusori, D.A., E.A. Caxton-Martins, S.T. Keji, P.O. Oluwayinka, T.A. Abayomi and S.A. Ajayi. 2008. Microarchitectural Adaptations in the Stomach of African Tree Pangolin (Manis tricuspis). International Journal of Morphology, 26(3): 701705.

Sun, G.Q. 2014. Chicken Anatomy and diagnosis of Chicken Disease. China Animal Health, 16(9): $55+94$.

Telford, I.R. and C.F. Bridgman. 1995. Introduction to functional histology, Second edition, Harper Collins College Publisher, New York, USA.

Wu, J. and C.L. Wang. 1995. The ants of China. China Forestry Publishing House, Beijing, China.

Wu, S., G. Ma, M. Tang, H. Chen and N. Liu. 2002. The status and conservation strategy of pangolin resource in China. Journal of Nature Resource, 17(2): 7.

Wu, S., N. Liu, Y. Li and R. Sun. 2005a. Observation on food habits and foraging behavior of Chinese pangolin (Manis pentadactyla). Chinese Journal of Applied and Environmental Biology, 11(3): 337-341.

Wu, S., G. Ma, Q. Liao and K. Lu. 2005b. Studies of conservation biology on Chinese Pangolin (Manis pentadactyla). China Forestry Publishing House, Beijing, China.

Zhang, Q.Y. 2004. Study on the Apparent Digestibility of Diet on Formasan Pangolin (Unpublished) PhD thesis, National Taiwan University, Taipei, Taiwan. 
Publisher's note: EScience Press remains neutral with regard to jurisdictional claims in published maps and institutional affiliations.

(C) (†)

Open Access This article is licensed under a Creative Commons Attribution 4.0 International License, which permits use, sharing, adaptation, distribution and reproduction in any medium or format, as long as you give appropriate credit to the original author(s) and the source, provide a link to the Creative Commons license and indicate if changes were made. The images or other third-party material in this article are included in the article's Creative Commons license, unless indicated otherwise in a credit line to the material. If material is not included in the article's Creative Commons license and your intended use is not permitted by statutory regulation or exceeds the permitted use, you will need to obtain permission directly from the copyright holder. To view a copy of this license, visit http://creativecommons.org/licenses/by/4.0/.

(C) The Author(s) 2020 . 